

\section{DISCLAIMER}

This report was prepared as an account of work sponsored by an agency of the United States Government. Neither the United States Government nor any agency Thereof, nor any of their employees, makes any warranty, express or implied, or assumes any legal liability or responsibility for the accuracy, completeness, or usefulness of any information, apparatus, product, or process disclosed, or represents that its use would not infringe privately owned rights. Reference herein to any specific commercial product, process, or service by trade name, trademark, manufacturer, or otherwise does not necessarily constitute or imply its endorsement, recommendation, or favoring by the United States Government or any agency thereof. The views and opinions of authors expressed herein do not necessarily state or reflect those of the United States Government or any agency thereof. 


\section{DISCLAIMER}

Portions of this document may be illegible in electronic image products. Images are produced from the best available original document. 


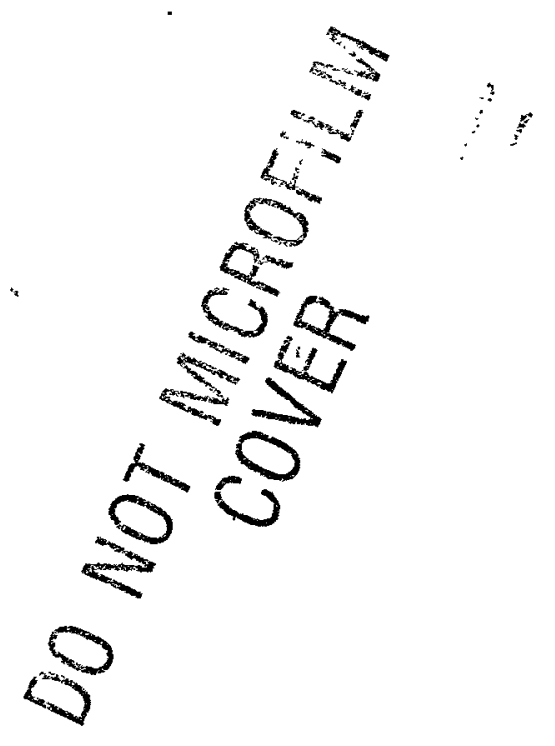

This work was supported by the US Department of Energy, Office of Safeguards and Security, and by the Program for Technical Assistance to IAEA Safeguards.

Edited by Sarah Kreiner, Group Q-1

Prepared by Jo Ann Barnes, Group Q-1

This report was prepared as an account of work sponsored by an Agency of the United States Government. Neither the United States nor the United States Department of Energy, nor any of their employees, nor any of their contractors, subcontractors, or their employees, makes any warranty, express or implied, or assumes any legal liability or responsibility for the accuracy, completeness or usefulness of any information, apparatus, product, or process disclosed, or represents that its use would not infringe privately owned rights. Further, neither the subject matter nor the content of this report reflects any policy. expressed or implied, by the United States Government. 
LA- $-9757-[H S$

LA-9757-MS

(ISPO-195)

DE83 013224

UC-15

Issued: April 1983

\title{
A Spent-Fuel Cooling Curve for Safeguard Applications of Gross-Gamma Measurements
}

\author{
P. Rinard
}

\section{DISCLAIMER}

\begin{abstract}
This report was prepared as an account of work sponsored by an agency of the United States Government. Neither the United States Government nor any agency thereof, nor any of their employees, makes any warranty, express or implied, or assumes any legal liability or responsibility for the accuracy, completeness, or usefulness of any information, apparatus, product, or process disclosed, or represents that its use would not infringe privately owned rights. Reference herein to any specific commercial product, process, or service by trade name, trademark, manufacturer, or otherwise does not necessarily constitute or imply its endorsement, recommendation, or favoring by the United States Government or any agency thereof. The views and opinions of authors expressed herein do not necessarily state or reflect those of the United States Government or any agency thereof.
\end{abstract}

PORTIONS OF THIS REPORT ARE ILLEGIBLE.
It has been remothce from the best
avaihable copy to perrit the broadest
possible availability.


CONTENTS

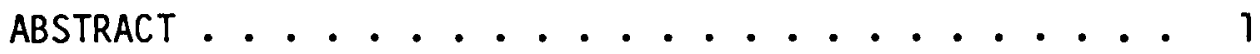

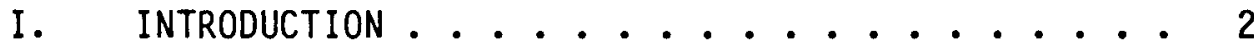

II. PROPERTIES OF THE COOLING CURVE ....... 3

A. The Form of the Curve ......... 3

1. Selecting the Form ......... 3

2. Uncertainties of the Curve ..... 6

3. The Curve's Form and Incorrect Data ... 7

B. The Curve-Fitting Technique ....... 9

III. GROSS-GAMMA MEASUREMENTS . . . . . . . . 10

A. Equipment and Techniques ........ 10

B. Summaries of Data .......... 11

1. PWR Fuel ............ 11

2. BWR FUe1 ............... 11

IV. APPLICATIONS TO MEASURED DATA ....... 15

A. PWR Measurements ......... 15

B. BWR Measurements .......... 17

v. APPLICATIONS TO CALCULATED DATA ...... 18

A. The Calculational Method......... 18

B. Sensitivity to Various Parameters ..... 19

1. Initial Enrichment ......... 21

2. Irradiation History ........ 21

3. Detector Distance .......... 26

4. Exposure .......... 26

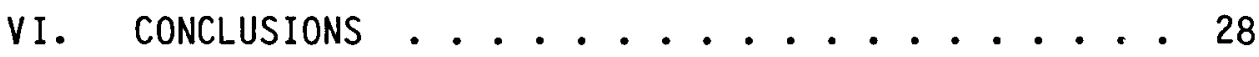

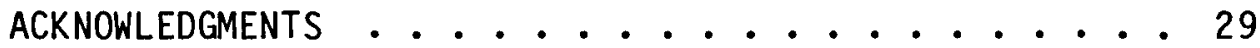

REFERENCES ................... 30 
A SPENT-FUEL COOLING CURVE FOR SAFEGUARD APPLICATIONS

OF GROSS-GAMMA MEASUREMENTS

by

P. Rinard

ABSTRACT

Gross-gamma detectors can be used to gather data from spent-fuel assemblies in a simple and rapid manner. Using these data, inspectors can generate a power-law curve to check the consistency of the declared values with the measured values; points outside the curve indicate erroneously declared values or removal of material. Simple types of erroneously declared values can be detected immediately, whereas subtle types may require a second measurement and more subtle types may escape detection.

If measurements of passive emissions of neutrons from the assemblies are made in addition to the gamma measurements, the values of the exposures and cooling times can be estimated independent of the operator-declared values. A7though not yet demonstrated, it may be possible to obtain crude estimates of the exposures and cooling times from the gamma measurements alone. 


\section{INTRODUCTION}

The objective of safeguards efforts by the International Atomic Energy Agency (IAEA) is the "timely detection of diversion of significant quantities of nuclear material from peaceful nuclear activities to the manufacturer of nuclear weapons..., and deterrence of such diversion by the risk of early detection." 1 Toward this end, IAEA inspectors have the task of verifying the integrity of nuclear fuel assemblies to assure that the assemblies have the expected fissile content after being removed from a nuclear reactor and kept in storage.

In conjunction with other techniques, the use of gross-gamma detectors (such as ionization chambers) to verify the nuclear content has been successfully demonstrated. ${ }^{2}$ By itself, a simple gross-gamma measurement cannot yield all the information that an inspector may desire, but it can be an important tool for the rapid inspection of a large number of assemblies. This report is concerned with methods of analyzing gross-gamma data so that the objectives of an inspection can be met as nearly as possible while using the simple gross-gamma measurement techniques.

The major difficulty in analyzing gross-gamma data is that assemblies with different histories of exposures and cooling times can produce the same response from the detector. An assembly that has had a low exposure and a short cooling time can produce the same gross-gamma signal as that produced by an assembly that has had a much greater exposure and a longer cooling time. The most that might be expected from a single set of such measurements is a consistency check of the operator's declared exposures and cooling times (although a method is suggested in Sec. V.B.4 by which more than mere consistency could possibly be obtained).

In repeating the measurements after even longer cooling times, the check on the declared values becomes much more demanding. Any assembly with values falsified, although previously consistent with other assemblies, is likely to appear inconsistent. If a large group of assemblies had been assigned incorrect values, it is likely that the proposed cooling curve will not fit the data with the expected quality, and attention will thereby be drawn to the assemblies.

By measuring the emission rates of neutrons from the assemblies, their exposures can be estimated with about $5 \%$ precision. ${ }^{3-7}$ The cooling curve 
described in this report can then provide the corresponding cooling times. Using this combination of measurements, the assemblies' parameters can be uniquely determined during one measurement session. The uses of neutron measurements will not be pursued to any depth in this report where gross-gamma applications are the main concern.

An important limitation in using gamma-ray techniques (whether they are gross-gamma or not) is that only gamma rays from near the surface of an assembly can be measured. 8 Even with allowing for the gaps between fuel pins, much of the fuel cannot be examined with gamma-ray techniques. Neutron measurements, however, do respond to neutrons emitted throughout more of the assembly, providing another reason for performing the two types of measurements on the same assembly. If only gamma-ray measurements are performed, reliance must be placed on physical inspection of the assembly and any protective seals in order to have some assurance that the gamma-ray information applies to the complete assembly.

\section{PROPERTIES OF THE COOLING CURVE}

A. The Form of the Curve

A gross-gamma detector provides a response (such as an electric current) that is only a relative number. The magnitude of the number depends in part on the exposure and cooling time of the assembly, both of which affect the atom densities of elements that produce the gamma rays. Other factors (for example, the type of medium between the assembly and the detector, the distance between the assembly and the detector, the absorbing materials in the detector) are considered unchanged during a measurement session with a set of assemblies. 9

1. Selecting the Form. A simple relationship has been found useful 10 in connecting a detector's response $R$ with the exposure $E$ and cooling time $T$ :

$$
R=a E T^{b}, \text { or } R / E=a T^{b} \text {, }
$$

where $a$ and $b$ are both constants for measurements on a set of assemblies in a single storage facility. 
Considering the complexities of the creation and decay of gamma-ray emitters in assemblies, it may seem surprising that Eq. (1) can even come close to a useful description of what is observed. But some theoretical justification of the form of the equation is possible. A more logical choice for the dependence on cooling time would be a sum of decaying exponentials, basically one term for each gamma-ray emitter. An exponent would have the product of a decay constant and the cooling time; the exponential would be weighted by the atom density of that isotope. (Complications for this function include the dependence of weighting on the exposure, the varying ability of gamma rays to penetrate the fuel and the surrounding water depending on their energies, build-up factors, and energy-dependent absorption in the detector.) A sum of exponentials, however, shows the same general behavior with cooling time as does a power law. Instead of decreasing with a regular half-life las does a single exponential), the time required for the sum to reach half of a previous value keeps growing with time, until the time is eventually so large that only one exponential is contributing significantly to the sum. A power law has the same behavior. Both these curves can be applied to the data of interest here, but the power law is of course preferred for its mathematical simplicity as long as it approximates the physical reality sufficiently well.

The linear dependence on exposure indicated in Eq. (1) is more difficult to justify and may not represent the true exposure function as well as does the power law for the cooling time dependence. If one gamma-ray emitting isotope is almost solely responsible for the detector's response, and if the atom density of that isotope is proportional to the assembly's exposure, then the factor $E$ in $E q . ~(1)$ would readily be justifiable. These conditions are almost met by ${ }^{137} \mathrm{Cs}$; its density is proportional to the exposure, ${ }^{3,11,12}$ and it can contribute the dominant portion of the dose in an ionization chamber, provided several years of cooling have passed. 3,9

To investigate the form of the curve further, results of a computer model of a pressurized-water reactor (PWR) fuel assembly were used. Atom densities were calculated ${ }^{13,14}$ after several exposures up to about $50 \mathrm{GWd} / \mathrm{tU}$ using a constant power level of $200 \mathrm{~W} / \mathrm{cm}$; they compare favorably with destructive ana 1 ysis results on the same type of fuel. 15

Another model of such an assembly was used to transport the gamma rays through water into an ionization chamber. ${ }^{3,9}$ For any given cooling time, the dependence of the dose rate in the detector on the assembly's exposure can be 
estimated. The curves in Fig. 1 show the relationships at nine cooling times. Before one year of cooling has elapsed, the rapidly decaying ${ }^{95} \mathrm{Zr}$ and ${ }^{95} \mathrm{Nb}$ prevent any semblance of a linear relationship from appearing. After one year, a straight line is a good approximation for higher exposures (al though the lines do not quite pass through the origin). More generally, for cooling times of 18 months or more, the response and exposure are related very well through a power 1aw:

$$
R=C E^{d}, T \geq 18 \text { months. }
$$

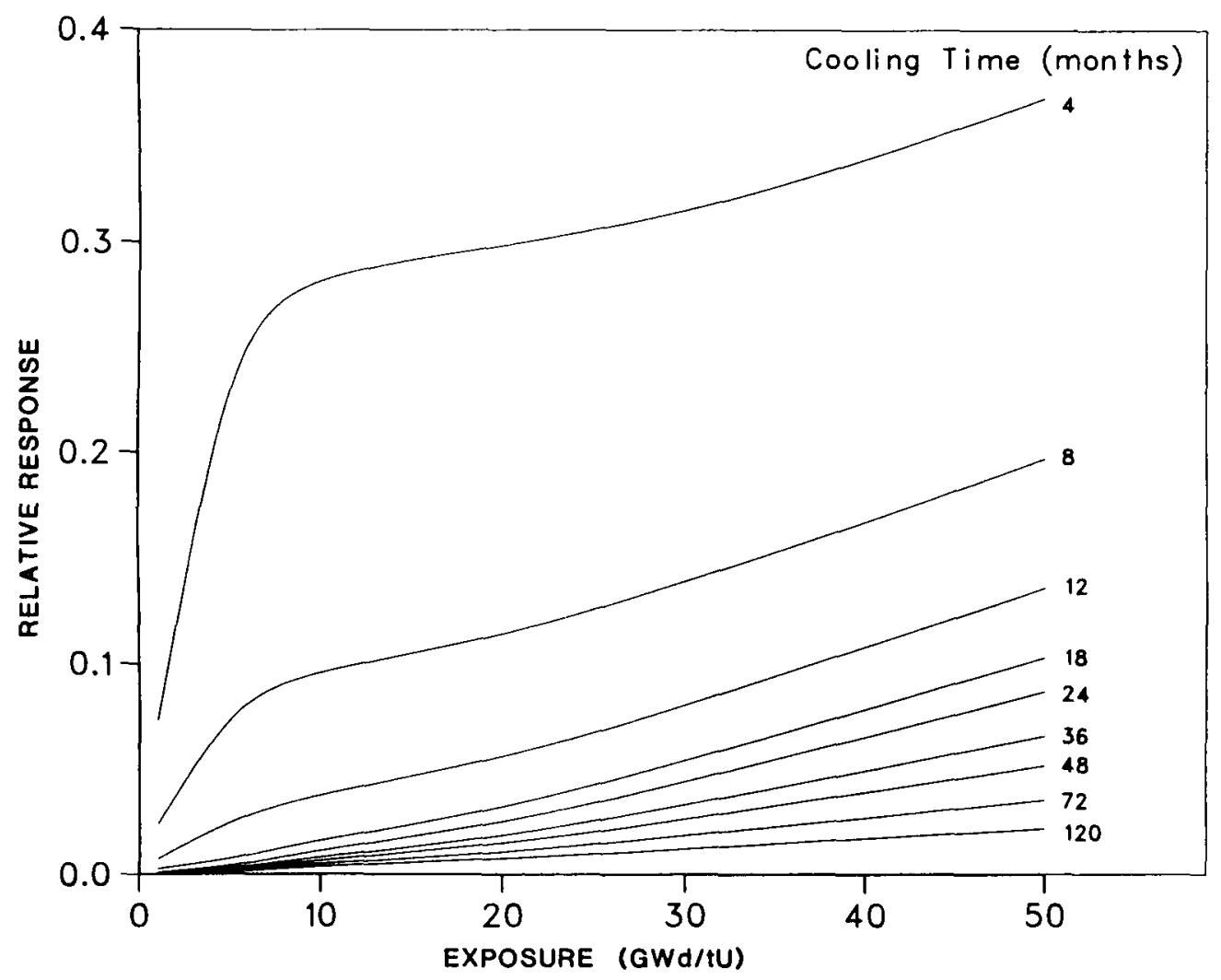

Fig. 1. The dependence of the gross-gamma detector's response is shown as a function of an assembly's exposure at various cooling times. The responses are calculated using models of assemblies within a reactor core and in an underwater storage position. During the first year of cooling, the form of the curve changes rapidly, but then takes on a fairly linear shape as assumed in Eq. (1) of the text. 
The value of the constant $c$ is not important; only $d$ affects the choice of the power of $E$ to be used in $E q$. (1). The power $d$ varies between 1.1 and 1.35 for cooling times between 18 and 120 months and exposures up to $50 \mathrm{GWd} / \mathrm{tU}$. After 36 months, d varies linearly with cooling time:

$$
d=1.415-0.00234 \mathrm{~T}
$$

The values of $d$ decrease rapidly to 1.2 as the time shortens from 36 to 18 months.

Al1 of these $d$ values are only slightly greater than 1 , so the assumption in Eq. (1) may seem reasonable. But even a power of 1.1 for $E$ can produce results $50 \%$ larger than does $E$ to the first power when the exposure is near $50 \mathrm{GWd} / \mathrm{tU}$. Nevertheless, Eq. (1) has worked well even for exposures up to $40 \mathrm{GWd} / \mathrm{tU}$ (see Sec. IV), and this simple form will be retained in this report.

2. Uncertainties of the Curve. The inevitable scatter in the data points affects not only the quality of the fit, but also the interpretation of the significance of data points that do not lie on the curve. Are such points within the normal bounds of scatter, or is there reason to investigate the data and declared values further? Some uncertainty bounds must be associated with the curve to guide the interpretation.

A commonly used statistical concept for curve fitting is that of the confidence limit. 16-19 From the quality of the fit to the points and the way in which the values of the independent variable are distributed, confidence limits are to show where future measurements are likely to fall with a specified degree of confidence. Applying this technique to the type of data encountered here produces results that are not useful. Typically, the fuel assemblies in a storage facility can be divided into several groups, with assemblies in each group having identical cooling times. When the R/E vS T plot is constructed, there will be many points at each rather isolated cooling time. The scatter in the R/E values has not been found to be unduly large as a rule, but the confidence limits on the curve fitted to these data points have not included as many of the data points as expected from the specified confidence 1evel. The expression for the confidence-limit width shows that when the data exist in 
clumps about a few values of the independent variable, the confidence limit is narrower than when the values are more uniformly distributed; that certainly is the case here. The width of the limits also depends on the choice of the standard error of observations of unit weight. ${ }^{16}$ The usual practice is to use its so-called unbiased estimate made by external consistency ${ }^{16}$ that forces the fit's chi-squared value to have its mean value (the number of degrees of freedom). This estimate is used when insufficient data are available to use the so-called estimate from internal consistency. In the cases here, internal consistency estimates can be deduced from the knowledge of the accuracies involved.

More useful here might be the statistical tolerance limits. ${ }^{20}$ These are limits inside of which a certain fraction of the values should lie. There is more than one way to calculate the width of these limits; they are estimated here through the use of expected errors in the measurements. The errors associated with the measurement are usually on the order of $1 \%, 6$ and the declared exposures typically have $5 \%$ uncertainties, ${ }^{21}$ so the uncertainties in the $R / E$ values are slightly more than 5\%. If curves are drawn using 1.05 and 0.95 times the fitted curve, the data points are almost always within these limits. Such curves are used in Sec. IV of this report to assist in judging whether a data point is sufficiently close to the fitted curve to be accepted as consistent with the curve. In essence, the estimate of the standard error of observations of unit weight has been made by internal consistency from the data and their known errors so that the widths of the confidence limits are always $5 \%$ of the fitted curve.

The errors in the longer cooling times are much less than 1\%, but those for short cooling times can be much greater because the absolute error in the cooling time is about the same for all assemblies.

3. The Curve's Form and Incorrect Data. Accepting Eq. (1) as the fitting equation, it is clear that it is invariant to multiplicative changes in the exposure or cooling time. In other words, all the exposures or cooling times can be multiplied by the same factor without disturbing the quality of the fit. The form is not invariant, however, to additive changes so that the quality of the fit is decreased by changing all the cooling times or exposures by the same amount. After being altered by an additive change, the data no longer fit onto a power-law curve as well as they did before the change was made. For example, 
for certain measured data described later in this report, a change in all the cooling times by 6 months led to a fit that passed through few of the data points related to cooling times less than 30 months. Such a poor fit can indicate the need for more investigation by an inspector.

An assembly might have declared values that are incorrect but still allow it to be placed on the curve after one measurement session. The incorrect values could result from an honest error or from an attempt to conceal the removal of fuel from within the assembly. The exposure and cooling time might not have to be changed to avoid detection from gamma-ray measurements (that do not respond to fuel from the center of assemblies), but must be changed to escape notice from neutron emission measurements. Thus, after one measurement session, the neutron and gamma-ray measurements can be consistent with the declared values of the assembly, but a second session a few months later can indicate a discrepancy.

If the declared exposure is reduced from $E$ to $E^{\prime}$ so that the point is still tolerably near the curve, the modification will never be detected. But if the $E^{\prime}$ is so small that the point is intolerably far from the curve, the cooling time must also be reduced from $T$ to $T^{\prime}$. The largest initially undetected errors occur if the first measurement places the data point on the lower tolerance limit. Then as time progresses, the data point will be found to move across the fitted curve and eventually intersect the upper tolerance limit. A second measurement at this or a later time will notice the error.

For a tolerance limit width $w$ that is a constant fraction of the fitted curve, the maximum undetected change in the cooling time is

$$
\left(T_{\text {true }}-T_{\text {false }}\right)_{\max }=T_{\text {true }}\left[1-\left(\frac{E / E^{\prime}}{T-W / b}\right] .\right.
$$

The time span between the first measurement and the later time at which detection is possible is

$$
T_{1 \text { ater }}-T_{\text {initial }}=T_{\text {initial }}\left[\frac{1-\left(\frac{E / E^{\prime}}{T-W}\right)^{1 / b}}{1-\left(\frac{E / E^{\prime}}{T+W}\right)^{1 / b}-1}\right] \text {. }
$$


Some numerical examples may assist in interpreting these equations. Assume that $b=-1$ and $w=0.1$. Further assume for now that $E / E^{\prime}=1 / 0.9$. If the initial measurement is made after a true cooling time of 6 months, a declared value of 5 months would be tolerable at that time and it would be 108 months later before an intolerable point would be reached. If the initial measurement is made after a true cooling time of 24 months, however, the declared time could be as small as 19 months without being detected for another 432 months! Now assume that $E / E^{\prime}=1 / 0.8$. For a measurement after 6 months of cooling, the declared time could be as small as 4 months and it would take only 8 more months to find the error. If the first measurement is after 24 months of cooling, 17 months could be the declared time and it would take only 32 more months to find the error.

To assure timely detection of diversion, it is clearly important to make measurements on spent fuel as early as possible after the fuel has been removed from a reactor. Reduction of the tolerance width to as small a value as possible is obviously of great importance.

\section{B. The Curve-Fitting Technique}

The parameters in Eq. (1) are determined by the curve-fitting technique of Deming. ${ }^{16,17}$ It is not necessary for the function to be linear in the parameters, so Eq. (1) is not linearized (by taking logarithms) and possible distortions in the fit are thus avoided. The two variables are treated in a symmetric fashion because this function is minimized:

$$
S=\sum_{i=1}^{N}\left\{w_{T_{i}}\left[T_{m_{i}}-T_{a_{i}}\right]^{2}+w_{R / E}\left[\left(\frac{R}{E}\right)_{m_{i}}-\left(\frac{R}{E}\right) a_{i}\right]^{2}\right\} .
$$

The sum on $i$ ranges over all the $\mathrm{N}$ data points. The weighting factors $w$ are typically the reciprocals of the squares of the uncertainties of the data values, and errors in both the $T$ and $R / E$ variables are allowed. The $m$ subscript denotes measured values; the a subscript is for the so-called adjusted values. Adjusted values are on the fitted curve and are estimates of the true values of $T$ and $R / E$ for each of the assemblies. Confidence in these estimates increases when the form of the curve has a firm physical basis. 
This technique minimizes the sums of squares of distances from the data points to the curve, using distances that are in the $T-(R / E) P l a n e$, not just distances parallel to the $R / E$ axis. If the errors in $T$ are quite small, the adjusted $T$ values will be equal to the measured $T$ values and the technique reduces to the usual one where the distances are computed parallel to the R/E axis.

\section{GROSS-GAMMA MEASUREMENTS}

\section{A. Equipment and Techniques}

The gross-gamma detectors most often used by Los Alamos National Laboratory Safeguards Assay personnel have been ionization chambers. ${ }^{2,3}$ A simple current-to-voltage amplifier connected the chambers to voltmeters in the early measurements, but later a portable microprocessor-based electronic unit was developed $3,22,23$ for both gamma-ray and neutron measurements on spent fuel. Called ION-1, this unit displays the measured values and their uncertainties.

In the measurements described below, one or more ionization chambers were lowered into the water of storage facilities inside a water-tight pipe or a polyethylene detector head. The fuel assemblies were raised completely or partially out of their racks and the ionization chambers were placed near the surfaces of the assemblies. Two detector heads held ionization chambers so that all four sides of an assembly could be measured simultaneously. Other heads had one or two chambers. When more than one side of an assembly is measured, the values can be summed to get a response that is more representative of the whole assembly.

Because the distance from an assembly to a detector can greatly affect the response, 3,9 provision was always made to be able to position the detector in a reproducible manner. When a single ionization chamber was used, the detector head was often attached to the storage rack, and assemblies were brought to the empty rack location beside the detector. When two or four detectors were used, the assembly was surrounded by the detector head with only a small separating water gap. 
B. Summaries of Data

Light-water reactor assemblies have been studied at several facilities by Los Alamos Safeguards Assay personnel. Enough assemblies were measured with ionization chambers at three of these facilities to enable cooling curve analyses to be performed. A discussion of the three studies follows.

1. PWR Fuel. At the Zion nuclear power plant, Zion, Illinois, 37 PWR assemblies were examined with a ring detector head that surrounded an assembly and measured its four sides simultaneously. ${ }^{6}$ Table I lists the pertinent parameters for the assemblies and the ionization chamber readings. The current-to-voltage amplifier was used; although no estimates of measurement errors were made, the errors can be considered to be about $1 \%$ in light of experiences with similar equipment elsewhere.

Fourteen PWR assemblies at the General Electric (GE) facility at Morris, Illinois, were studied; the results are summarized in Table 11.4,6,22-25 These assemblies had been received from three different reactors. In this case, two detector systems were used. Four ionization chambers were placed around an assembly that had been pulled partially out of $i$ ts storage rack. The assembly was then totally removed from the rack and taken to a positioning bracket attached to the wall of the storage pond; this bracket held the assembly in a reproducible position, while an ionization chamber reading was taken from each corner of the assembly. The sets of data from the assemblies' sides and corners form essentially the same cooling curve; in Table II the response shown from an assembly is actually the sum of the responses from the sides and the average of those from the corners. Because of the use of the positioning bracket, the gross-gamma measurements were reproducible to within about $0.6 \%$. Responses from different corners of an assembly were found to vary by as much as $49 \%$, with $20 \%$ or less being more typical. The precision of the gross-gamma measurements was about $1 \%$.

2. BWR Fue1. The results from 36 boiling-water reactor (BWR) assemblies measured at the Vermont Yankee power plant at Vernon, Vermont, are given in Table III. 26 The detector head held two ionization chambers so that opposite sides of an assembly could be measured simultaneously. The measurements were sums of the responses from the two ionization chambers. The choice of which 
TABLE I

GROSS-GAMMA RESPONSES FROM ASSEMBLIES AT ZIONa

\begin{tabular}{l} 
Declared \\
Exposure \\
(GWd/tU) \\
\hline
\end{tabular}

39.025

38.694

35.086

38.860

32.564

36.278

33.530

33.764

33.192

33.917

35.055

35.536

26.852

30.665

29.699

30.675

31.070

31.280

30.551

30.546

31.080

30.836

30.668

29.875

27.876

30.571

19.619

19.941

19.723

19.728

19.956

20.010

20.223

19.174

18.845

18.932

18.813

\begin{tabular}{cc}
$\begin{array}{c}\text { Declared } \\
\text { Cooling Timeb } \\
\text { (Months) }\end{array}$ & $\begin{array}{c}\text { Gross-Gamma } \\
\text { Response } \\
\text { (Relative) }\end{array}$ \\
\hline
\end{tabular}

$4.0 \pm 0.4$

3338

3326

3403

3430

3232

$10.0 \pm 0.4$

1432

1413

1391

1365

1389

1433

1360

$17.0 \pm 0.4$

703

829

800

770

885

$22.1 \pm 0.3$

$30.1 \pm 0.3$
699

658

660

645

645

675

648

586

667

332

333

301

317

343

327

329

246

249

247

252
Response Divided by Exposure

85.53

85.96

96.99

88.27

99.25

39.47

42.14

41.20

41.12

40.95

40.88

38.27

26.2

27.0

26.9

25.1

27.5

22.3

21.5

21.6

20.7

20.9

22.0

21.6

21.0

21.8

16.9

16.7

15.3

16.1

17.2

16.3

16.3

12.8

13.2

13.1

13.4

aThese previously unpublished data were obtained by $D$. M. Lee, J. R. Phillips, and J. K. Halbig, Los Alamos National Laboratory. bApplies for the exposures in each set. 
TABLE II

GROSS-GAMMA RESPONSES FROM ASSEMBLIES AT GE MORRIS

\begin{tabular}{|c|c|c|c|}
\hline $\begin{array}{l}\text { Declared } \\
\text { Exposure } \\
\text { (GWd/tU) } \\
\end{array}$ & $\begin{array}{c}\text { Declared } \\
\text { Cooling Timea } \\
\text { (Months) } \\
\end{array}$ & $\begin{array}{c}\text { Gross-Gamma } \\
\text { Response } \\
\text { (Relative) } \\
\end{array}$ & $\begin{array}{c}\text { Response } \\
\text { Divided by } \\
\text { Exposure } \\
\end{array}$ \\
\hline $\begin{array}{l}32.82 \\
33.08 \\
37.85 \\
40.07 \\
40.55\end{array}$ & $51.8 \pm 0.3$ & $\begin{array}{l}1856 \\
1888 \\
2275 \\
2378 \\
2396\end{array}$ & $\begin{array}{l}56.55 \\
57.07 \\
60.11 \\
59.35 \\
59.09\end{array}$ \\
\hline $\begin{array}{l}28.90 \\
31.71\end{array}$ & $64.1 \pm 0.3$ & $\begin{array}{l}1274 \\
1541\end{array}$ & $\begin{array}{l}44.08 \\
48.60\end{array}$ \\
\hline $\begin{array}{l}23.43 \\
26.91\end{array}$ & $67.4 \pm 0.3$ & $\begin{array}{r}989 \\
1158\end{array}$ & $\begin{array}{l}42.2 \\
43.03\end{array}$ \\
\hline $\begin{array}{l}18.47 \\
20.81 \\
20.84 \\
20.91\end{array}$ & $80.4 \pm 0.3$ & $\begin{array}{l}664 \\
770 \\
768 \\
742\end{array}$ & $\begin{array}{l}36.0 \\
37.0 \\
36.9 \\
35.5\end{array}$ \\
\hline 23.57 & $86.8 \pm 0.3$ & 736 & 31.2 \\
\hline
\end{tabular}


TABLE III

GROSS-GAMMA RESPONSES FROM ASSEMBLIES AT VERMONT YANKEE

\begin{tabular}{l} 
Declared \\
Exposure \\
(GWd/tU) \\
\hline
\end{tabular}

20.97

28.08

28.77

26.09

28.76

28.14

27.74

27.91

23.22

22.05

24.04

18.60

18.91

17.53

18.85

18.23

18.37

18.25

18.94

17.10

20.02

22.05

16.96

20.04

18.25

18.30

18.23

17.68

17.75

10.36

11.06

10.10

8.54

9.74

9.01

8.55

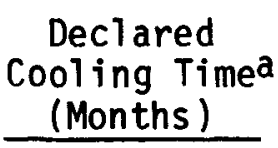

$7.0 \pm 0.3$

$20.0 \pm 0.3$

$32.0 \pm 0.3$

$38.0 \pm 0.3$

$44.0 \pm 0.3$

$57.0 \pm 0.3$

$91.0 \pm 0.3$

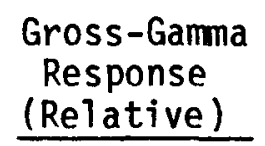

$\begin{array}{ll}573.0 & \pm 0.3 \\ 1602 & \pm 1 \\ 1656 & \pm 2 \\ 1020 & \pm 1 \\ 1656 & \pm 4 \\ 1463 & \pm 2 \\ 1473 & \pm 1 \\ 1485 & \pm 1\end{array}$

$491.3 \pm 0.9$

$420.2 \pm 0.3$

$469.0 \pm 0.5$

$251.6 \pm 0.7$

$205.7 \pm 0.3$

$231.8 \pm 0.9$

$244.4 \pm 0.3$

$221 \pm 2$

$232.5 \pm 0.8$

$264.0 \pm 0.3$

$204.4 \pm 0.3$

$274.9 \pm 0.3$

$247.4 \pm 0.5$

$204.7 \pm 0.3$

$174.6 \pm 0.4$

$223.2 \pm 0.3$

$178.7 \pm 0.3$

$174.4 \pm 0.4$

$178.3 \pm 0.3$

$176.9 \pm 0.9$

$175.7 \pm 0.3$

$67.42 \pm 0.08$

$60.55 \pm 0.08$

$54.35 \pm 0.08$

$53.59 \pm 0.08$

$64.66 \pm 0.08$

$54.68 \pm 0.08$

$57.64 \pm 0.08$ \begin{tabular}{c} 
Response \\
Divided by \\
Exposure \\
\hline
\end{tabular}

27.32

57.05

57.55

39.10

57.58

51.99

53.10

53.21

21.16

19.06

19.51

13.53

10.88

13.22

12.97

12.12

12.66

14.47

10.79

12.57

12.36

9.283

10.29

11.14

9.79

9.53

9.78

10.01

9.899

6.507

5.475

5.381

6.275

6.639

6.069

6.742

applies for the exposures in each set. 
two sides to measure made no significant difference in the final result. The ION-1 electronics unit was used for the measurements, and estimates of the measurement uncertainties were made by that unit.

\section{APPLICATIONS TO MEASURED DATA}

In this section, the cooling curve and its interpretations described in Sec. II are applied to the data described in Sec. III.

\section{A. PWR Measurements}

The data from the Zion facility (Table I) produced the graph shown in Fig. 2. For the fit, the one-standard-deviation error in each cooling time was taken to be 0.35 month; ideally, the cooling time could be known more accurately, even with the complication of a gradual shutdown before the fuel was discharged, but the discharge dates readily available for use were given only by the month and year. The errors in detector response are difficult to assess accurately, but they are considered to be much smaller than those associated with operator-declared values of the exposures, which are chosen to be a conservatively small 5\%. So the fit was done with absolute errors of 0.35 month for all the cooling times and relative errors of $5 \%$ for all the R/E ratios.

The power-1aw function that best fits these data is $279.3 T^{-0.831}$; curves that differ from this by $5 \%$ are shown in Fig. 2 by dashed lines. Nearly all the data points fit between these dashed lines, indicating that the operatordeclared values form a generally consistent set.

At long cooling times, the R/E values at any one cooling time are nearly the same. At short cooling times, enough variation is found among the values at a single cooling time so that some points lie outside the $5 \%$ limit curves. In Fig. 2, the two data points that lie above the curves at the 4-month position would lie within the limits of the curve if the cooling times of the corresponding assemblies were reduced by about the uncertainty assigned to them $(0.35$ month $)$. There are isotopes present upon discharge with half-lives on the order of a few months, and their amounts may vary according to the location of the assembly in the core. The complication these short-lived isotopes introduce into the gamma emissions is gone after a year or two of cooling. With 


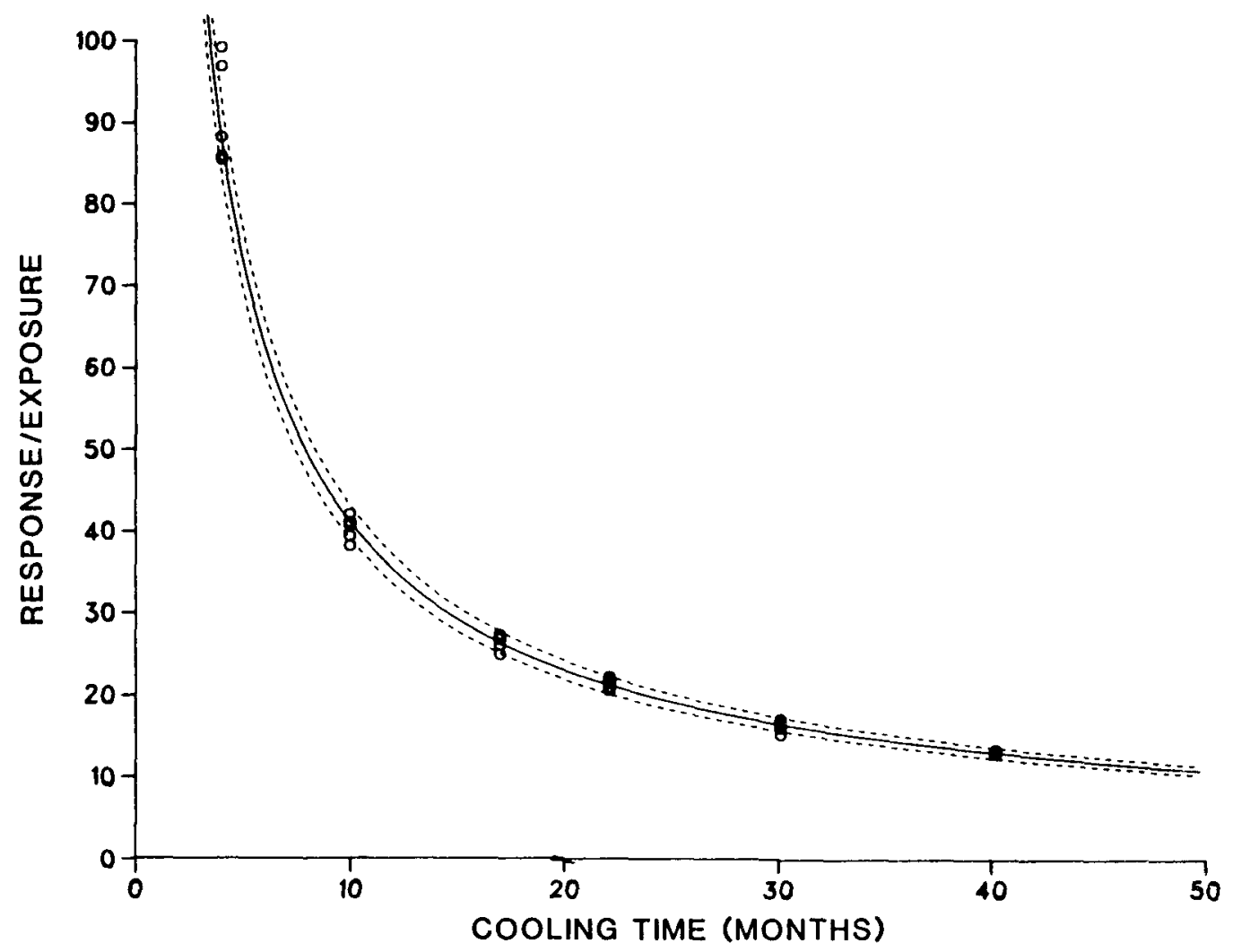

Fig. 2. The power-law cooling curve assumed in Eq. (1) of the text is fitted to measured values from the Zion nuclear power plant using Deming's method. (Each data point is shown by an open circle; the darkened regions are due to overlapping circles.) The estimated errors in the cooling times are about as wide as the circles marking data points; the errors in the $R / E$ values are assumed to be $5 \%$. The solid line is the fitted curve, 279.3-0.831. The dashed lines show $5 \%$ variations from the fitted curve and form tolerance limits within which most present and future data points are expected to be found, assuming that the declared exposures and cooling times are correct to about that accuracy.

these difficulties of interpretation in mind, the PWR assembly data from the Zion facility seem quite consistent with the operator-declared values.

The smaller set of data from the Morris storage facility (Table II) is shown in Fig. 3. The range of cooling times is not as great in this case, with very short times not represented. The data points fit within the 5\% 1 imits about the power-1aw function $4847 T^{-1.12}$. When these data are merged with the Zion data, ${ }^{8}$ a wider range of cooling times is available and the value of $b$ becomes -1.02 . 


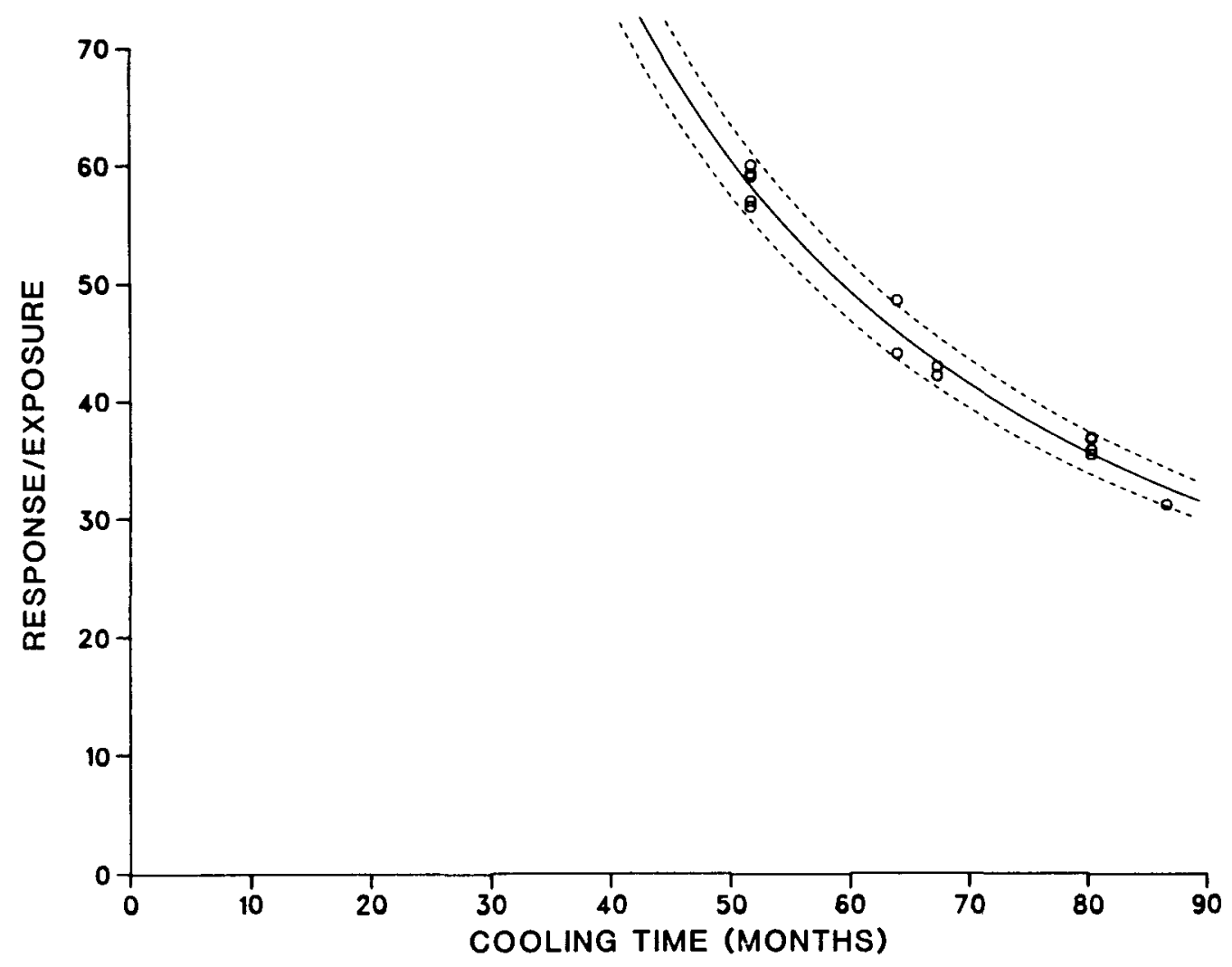

Fig. 3. The caption to Fig. 2 applies here, except that this graph is for the Morris storage facility and the fitted curve is $4847 \mathrm{~T}-1.12$.

\section{B. BWR Measurements}

Assemblies with a wide variety of irradiation histories at a BWR facility were measured at the Vermont Yankee plant. The data (Table III) and fitted curve are shown in Fig. 4. The curve is $205.7 \mathrm{~T}^{-0.784}$.

The most apparent feature in the curve is the large range of $R / E$ values at the 7-month cooling-time position, as seen in the Zion data for 4 months of cooling. One point is exceptionally below the curve. In some cases, the position of this point could indicate an assembly whose declared values are inconsistent with the others, and further investigation of the assembly would be needed. In this case, the assembly had an unusual irradiation history; it had been removed from the core for two cycles after being irradiated for two cycles, and then replaced for a third irradiation. The other assemblies had not had any such interruption in their irradiations. The declared exposure and cooling time (since the last irradiation cycle) for the assembly are 


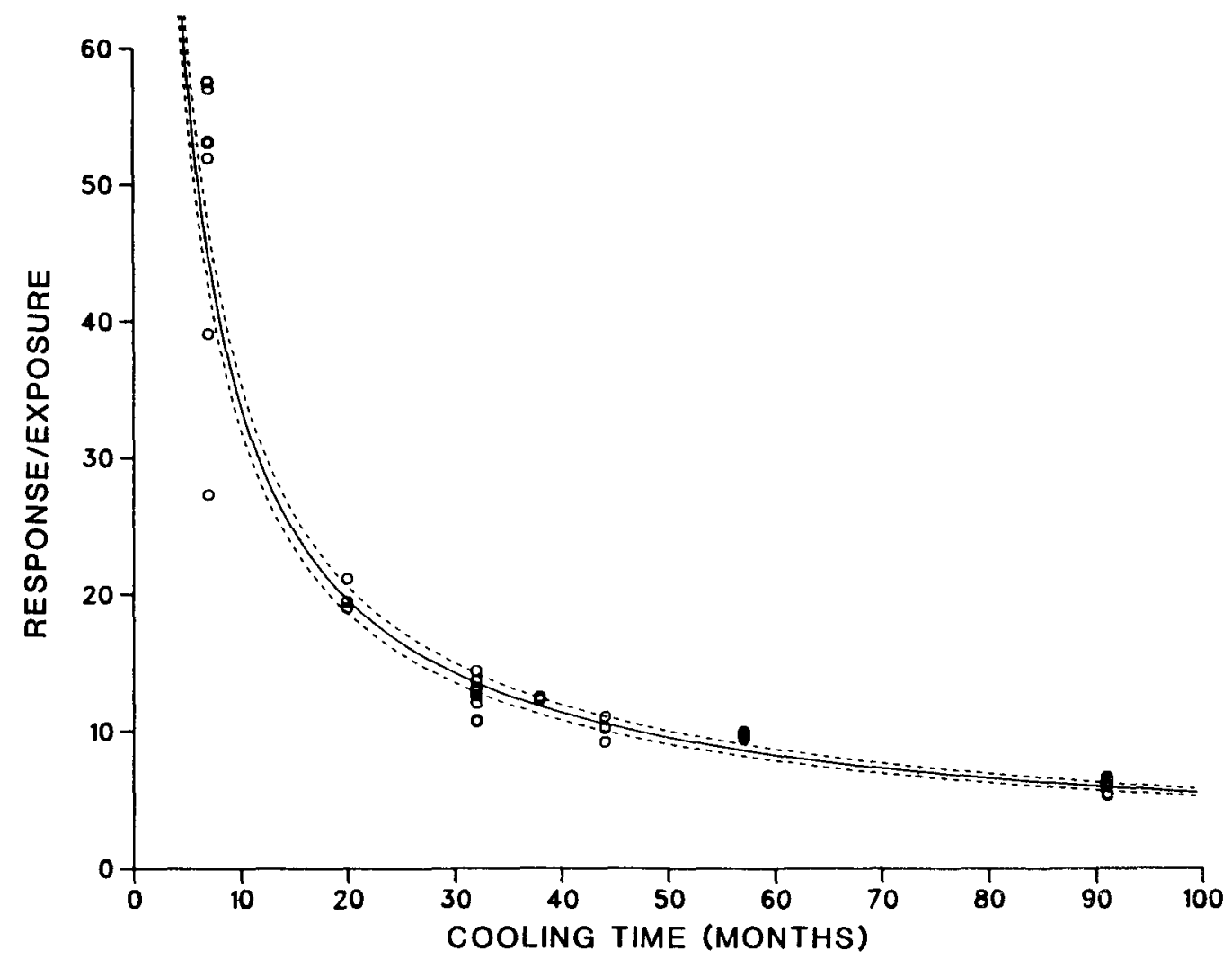

Fig. 4. The caption to Fig. 2 applies here, except that this graph is for the Vermont Yankee power plant and the fitted curve is $205.7 T-0.784$.

probably as accurate as for the other assemblies, but the mixture of isotopes present after the declared cooling time of 7 months did not match that of the companion assemblies. As noted in Sec. V.B.2, the difference in irradiation history should not have such a large effect. The origin of the fluctuations at very short cooling times needs further study.

other points for cooling times between 32 and 48 months are beyond the $5 \%$ uncertainty curves. It seems unlikely that errors in the declared cooling times are of much importance here, so perhaps the difficulty of calculating exposures with accuracies as good as $5 \%$ is the cause of these discrepancies.

\section{APPLICATIONS TO CALCULATED DATA}

A. The Calculational Method

The results in the previous section indicate that the simple cooling curve of Eq. (1) can have practical applications. With the limited experimental data 
available, however, it is not possible to study the properties of the curve in regard to such parameters as the initial enrichment of the fuel, its irradiation history, and the distance between the fuel and the gross-gamma detector. To examine the effects of these parameters, a model of a fuel assembly and detector has been used to generate simulated detector responses. It is then easy to change the parameters mentioned and to determine the sensitivity of the curve to the values of the parameters.

The model needs the atom densities of the isotopes that produce the gamma rays. These have been calculated for a PWR assembly ${ }^{13,14}$ and found to be quite accurate when compared to destructive analysis measurements. ${ }^{15}$ From high-resolution gamma-ray spectroscopy studies of irradiated fuels, ${ }^{3-5}$ the major producers of gamma rays within irradiated fuel assemblies are known. The 8 isotopes with 30 gamma-ray energies that were used in the present calculations are listed in Table IV. By knowing the atom densities of the isotopes immediately after irradiation and by using the known decay constants, the source strengths of these gamma rays can be calculated for a later time. The gamma rays must still be transported to the detector and absorbed in the active material in the detector. A calculational procedure for predicting this transport effect has been developed ${ }^{9}$ and is used here.

The calculations have the gamma rays travel through a portion of the assembly and then through water between the assembly and the detector, just as in the case of irradiated fuels in a storage pond. Because the water both absorbs and scatters the gamma rays, these effects are taken into account. The active absorbing material in the detector is assumed to be air, the substance used in the actual ionization chambers. The results of the calculations are relative numbers, as are the experimental data.

\section{B. Sensitivity to Various Parameters}

If the cooling curve is strongly affected by small changes in the parameters that describe the fuel assembly or the experimental conditions, the usefulness of the curve is diminished. However, only the range of exposures of the assemblies included in the process has any important effect. Before concentrating on that parameter, it first will be demonstrated that three other parameters are not important. 
TABLE IV

GAMMA-RAY SOURCES FOR THE CALCULATIONS

\begin{tabular}{|c|c|c|c|}
\hline Is sotope & $\begin{array}{l}\text { Half-Life } \\
\text { (Months) } \\
\end{array}$ & $\begin{array}{c}\text { Gamma-Ray } \\
\text { Energy } \\
\text { (MeV) } \\
\end{array}$ & $\begin{array}{c}\text { Branching } \\
\text { Ratio } \\
\end{array}$ \\
\hline $95 \mathrm{Zr}$ & 2.152 & $\begin{array}{l}0.72418 \\
0.75671\end{array}$ & $\begin{array}{l}0.4423 \\
0.546\end{array}$ \\
\hline $95 \mathrm{Nb}$ & $2.152^{a}$ & 0.76584 & 0.9927 \\
\hline${ }^{103} \mathrm{Ru}$ & 1.301 & $\begin{array}{l}0.49708 \\
0.61033\end{array}$ & $\begin{array}{l}0.8637 \\
0.0547\end{array}$ \\
\hline${ }^{106} \mathrm{Rh}$ & 12.12 & $\begin{array}{l}0.5118 \\
0.6218 \\
1.0501 \\
1.128 \\
1.562\end{array}$ & $\begin{array}{l}0.205 \\
0.0975 \\
0.015 \\
0.00383 \\
0.0015\end{array}$ \\
\hline${ }^{134} \mathrm{Cs}$ & 24.72 & $\begin{array}{l}0.60466 \\
0.79576 \\
0.80184 \\
1.0385 \\
1.16786 \\
1.36513\end{array}$ & $\begin{array}{l}0.976 \\
0.854 \\
0.0873 \\
0.01 \\
0.018 \\
0.0304\end{array}$ \\
\hline $137 \mathrm{Cs}$ & 361.2 & 0.66164 & 0.851 \\
\hline $144 \mathrm{pr}$ & $9.344^{a}$ & $\begin{array}{l}0.69649 \\
1.48915 \\
2.18562\end{array}$ & $\begin{array}{l}0.0135 \\
0.0027 \\
0.0067\end{array}$ \\
\hline${ }^{154} \mathrm{Eu}$ & 103.1 & $\begin{array}{l}0.6925 \\
0.7233 \\
0.7567 \\
0.8732 \\
0.9963 \\
1.0048 \\
1.1284 \\
1.2748 \\
1.3978 \\
1.673\end{array}$ & $\begin{array}{l}0.0165 \\
0.191 \\
0.041 \\
0.113 \\
0.107 \\
0.176 \\
0.011 \\
0.336 \\
0.016 \\
0.017\end{array}$ \\
\hline
\end{tabular}

aEffective half-life as a result of being in equilibrium with a parent. 
1. Initial Enrichment. There is no question that the atom densities and neutron emission rates from irradiated fuels are strongly affected by the initial enrichment of the uranium in the fuel. 7,27 In this study, however, the initial enrichment has no significant effect on the shape of the cooling curve; the value of $b$ in Eq. (1) is hardly affected, although the value of a changes somewhat. The unchanging value of $b$ is due to the way in which the atom densities were calculated. The power level was always the same, so that an assembly with a higher initial enrichment also had a lower neutron fluence after a given exposure had been reached. The main result was a lower production of transuranic isotopes, which have no role in the gamma-ray measurements. After the given exposure had been reached, there were the same number of fissions regardless of the enrichment and the same set of fission products and their gamma rays.

This lack of significance was shown by performing calculations with the detector placed $5 \mathrm{~cm}$ from the assembly and assuming different combinations of exposures; the initial enrichments were set at $2.56,3$, and $4 \%$. Over this range of enrichments, the same cooling curve was calculated to within a few per cent, which is less than the errors in the operator-declared values 21 and not considered to be a large enough effect to warrant retaining more than one initial enrichment in the remaining calculations. The $2.56 \%$ initial enrichment value was used for the rest of the calculations.

2. Irradiation History. In the calculations of the atom densities, the power level was usually held constant (at $200 \mathrm{~W} / \mathrm{cm}$ ) until the desired exposure was reached. The exposures were also reached with various combinations of less regular times in and out of a reactor. An assembly, for example, may be continuously irradiated for two years, removed for one year, then replaced in the reactor for another year. Much more complicated histories were devised and found to have noteworthy effects on neutron emissions in some cases. ${ }^{7}$ But in the gamma-ray calculations for the cooling curve, the history had even less effect than did the initial enrichment. The major portion of the detector response was due to isotopes with fairly long half-lives (the two cesium isotopes and europium); ${ }^{3,9}$ their gamma emissions are not very sensitive to the irradiation history. The contributions made by each isotope after various constant irradiations are shown in Figs. 5 and 6 . 
N

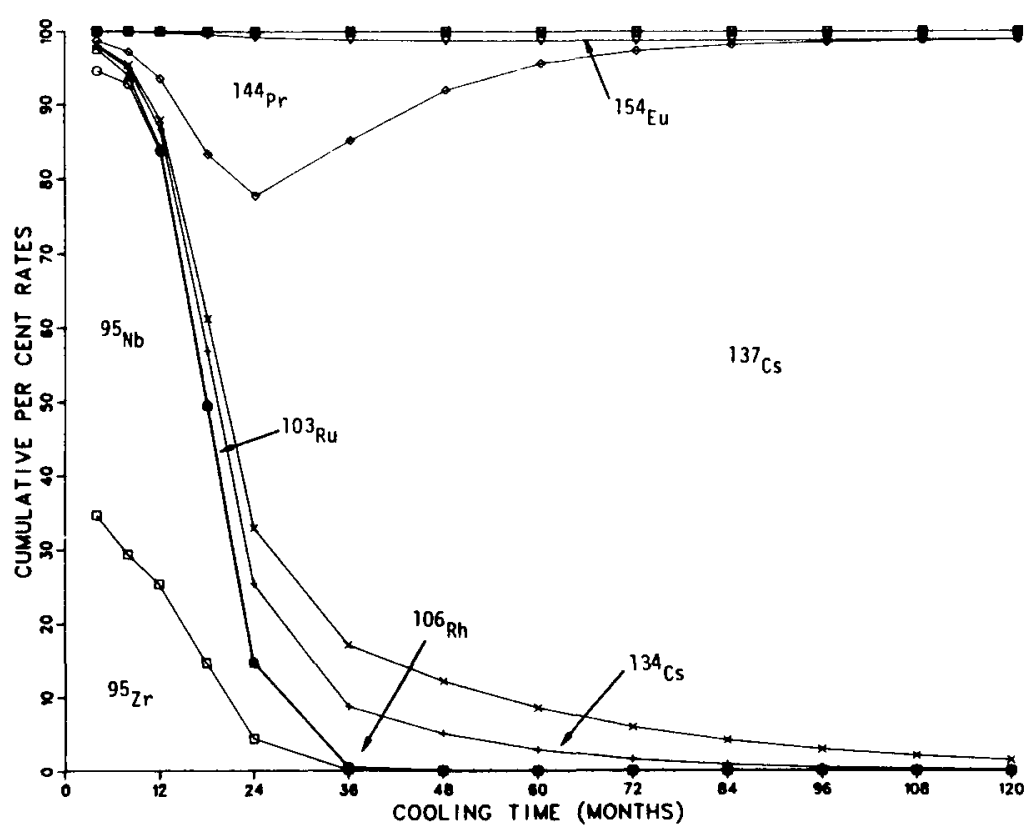

(a)

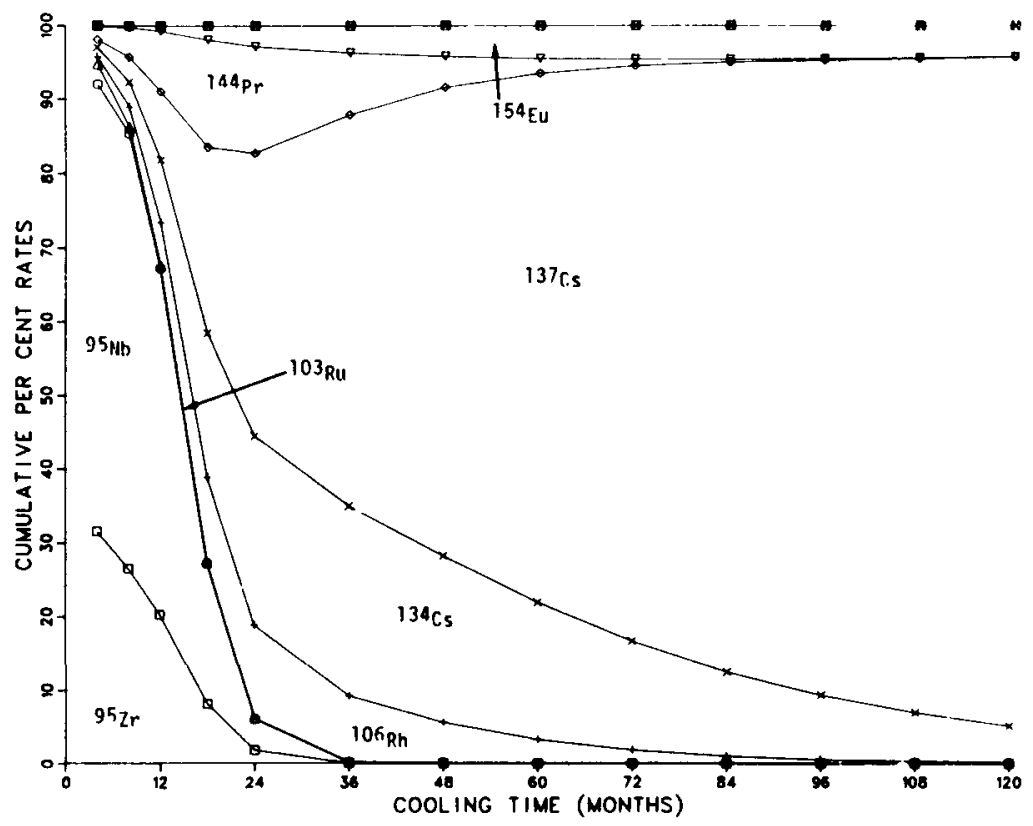

(b)
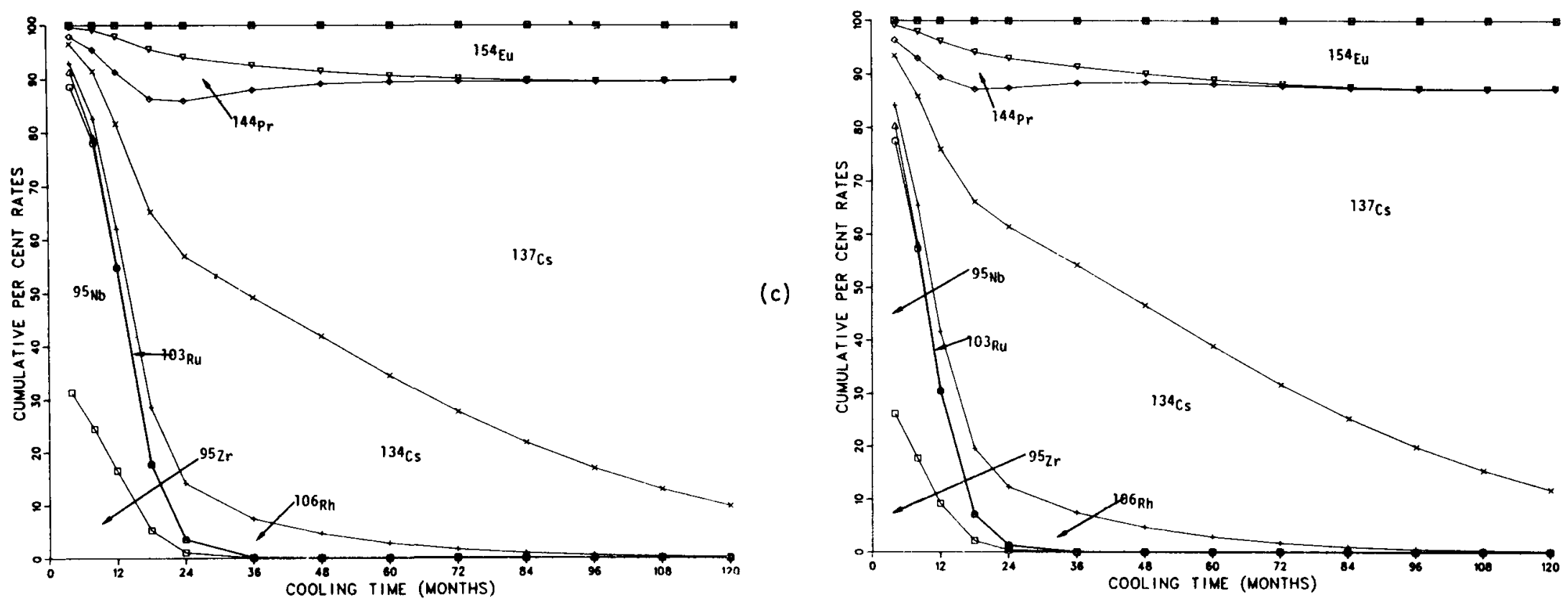

(d) 


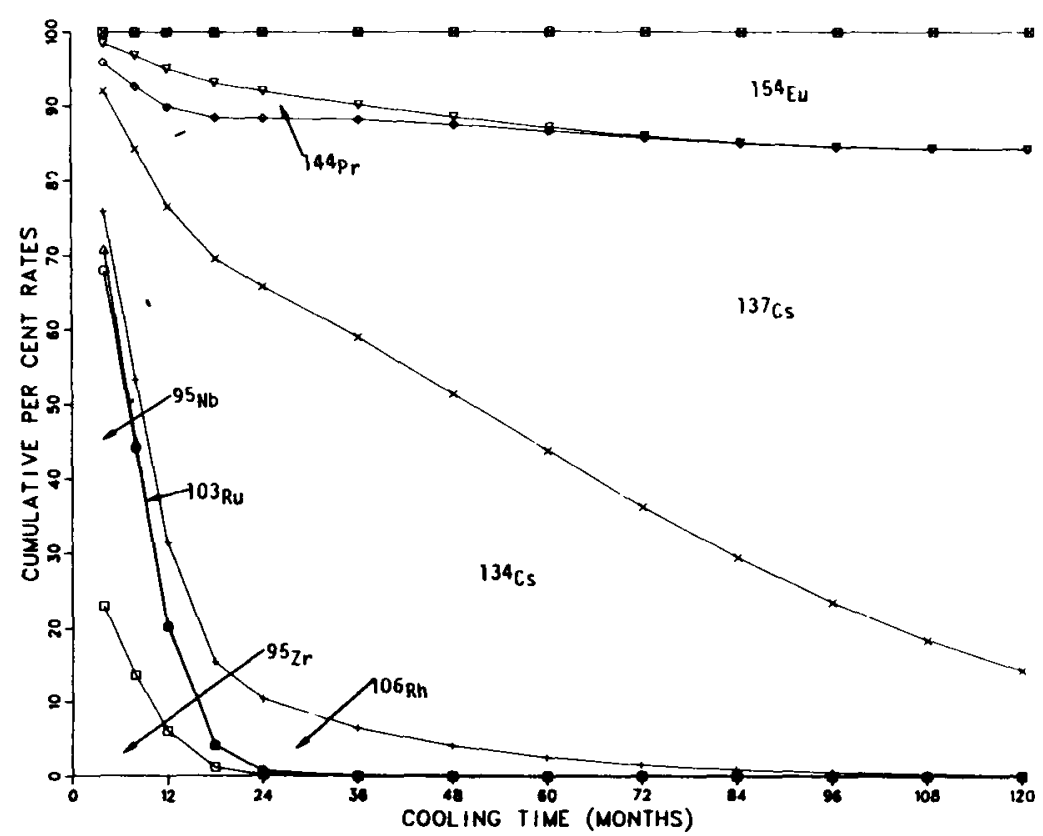

(e)

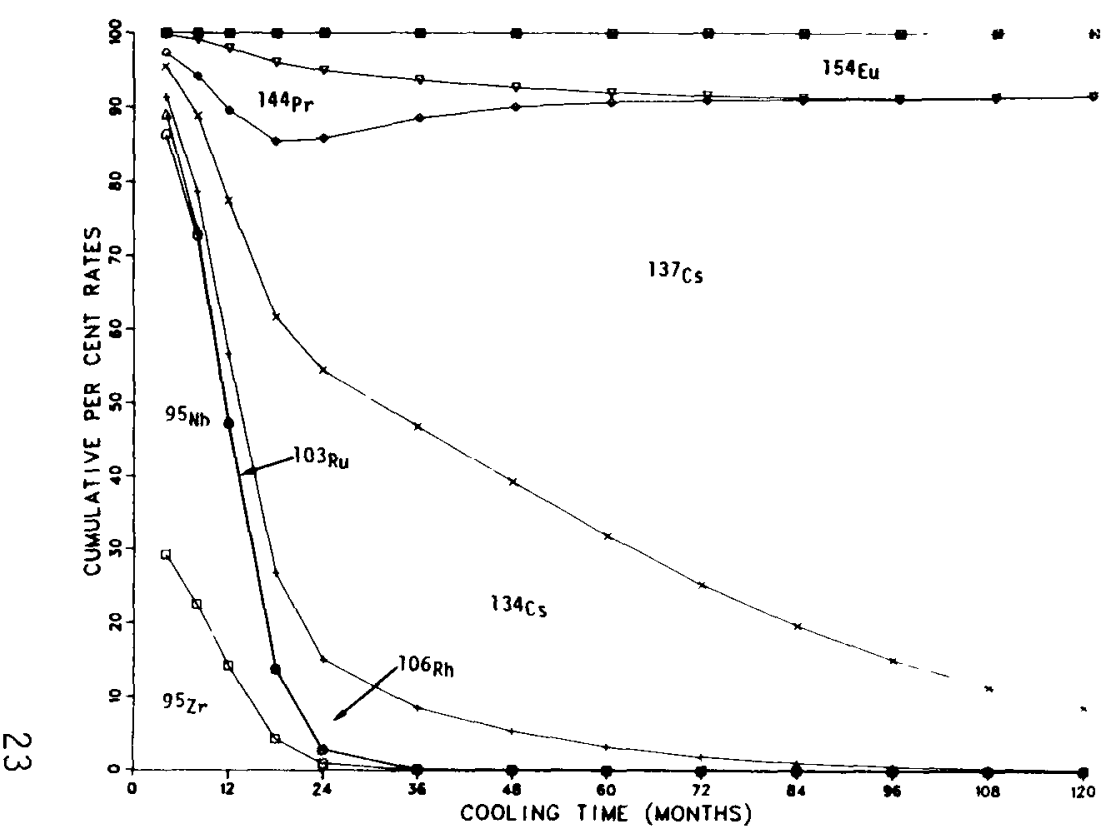

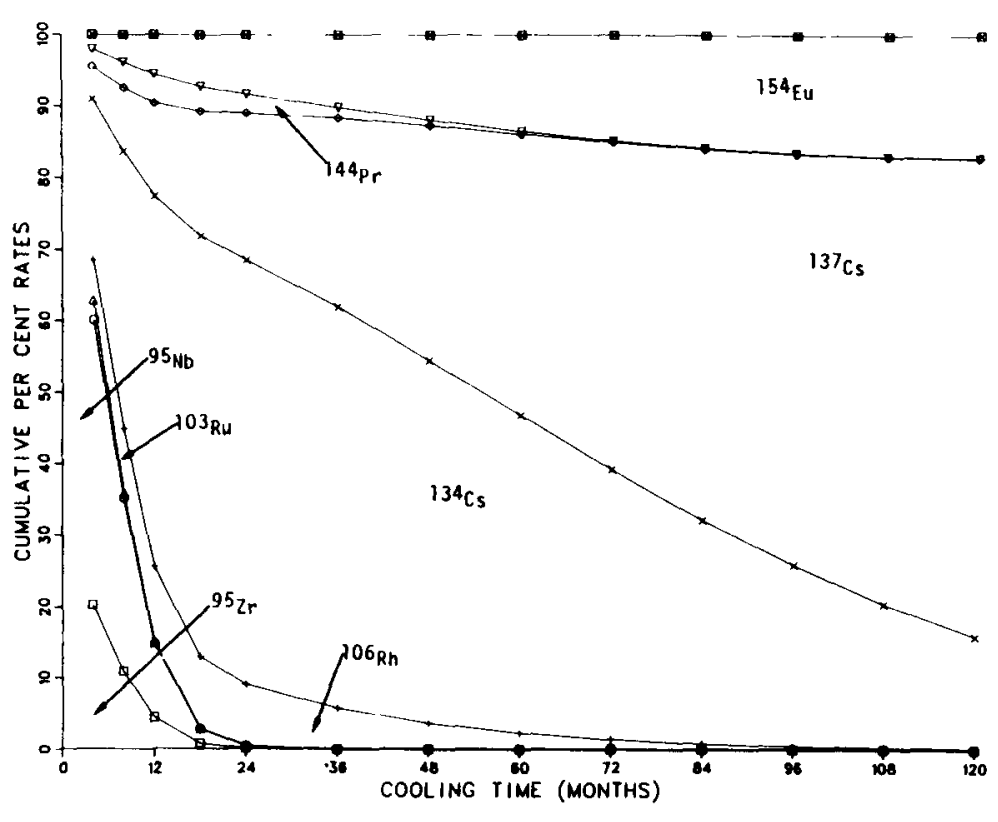

(f)

Fig. 5. Relative dose rates in an air-filled chamber placed $5 \mathrm{~cm}$ from the sides of irradiated fuel assemblies were calculated using 30 gamma rays from the 8 most significant isotopes in the assenibly. The contribution from each isotope at some cooling time is shown in this figure as the vertical distance between two of the curves. At all cooling times, the sum of the per cent contributions from all the isotopes is 100. (The per cent rates for $103 \mathrm{Ru}$ are nearly zero for cooling times greater than 6 months, so a $103_{\mathrm{Ru}}$ labe 1 points at two very closely spaced lines.) Each diagram is for a set of assemblies with a particu1 ar range of exposures in GWa/tU: (a) 0.1 to 5; (b) 5 to 10 ; (c) 10 to 20 ; (d) 20 to 30 ; (e) 30 to 40 ; (f) 40 to 50 ; (g) 0.1 to 50 . 

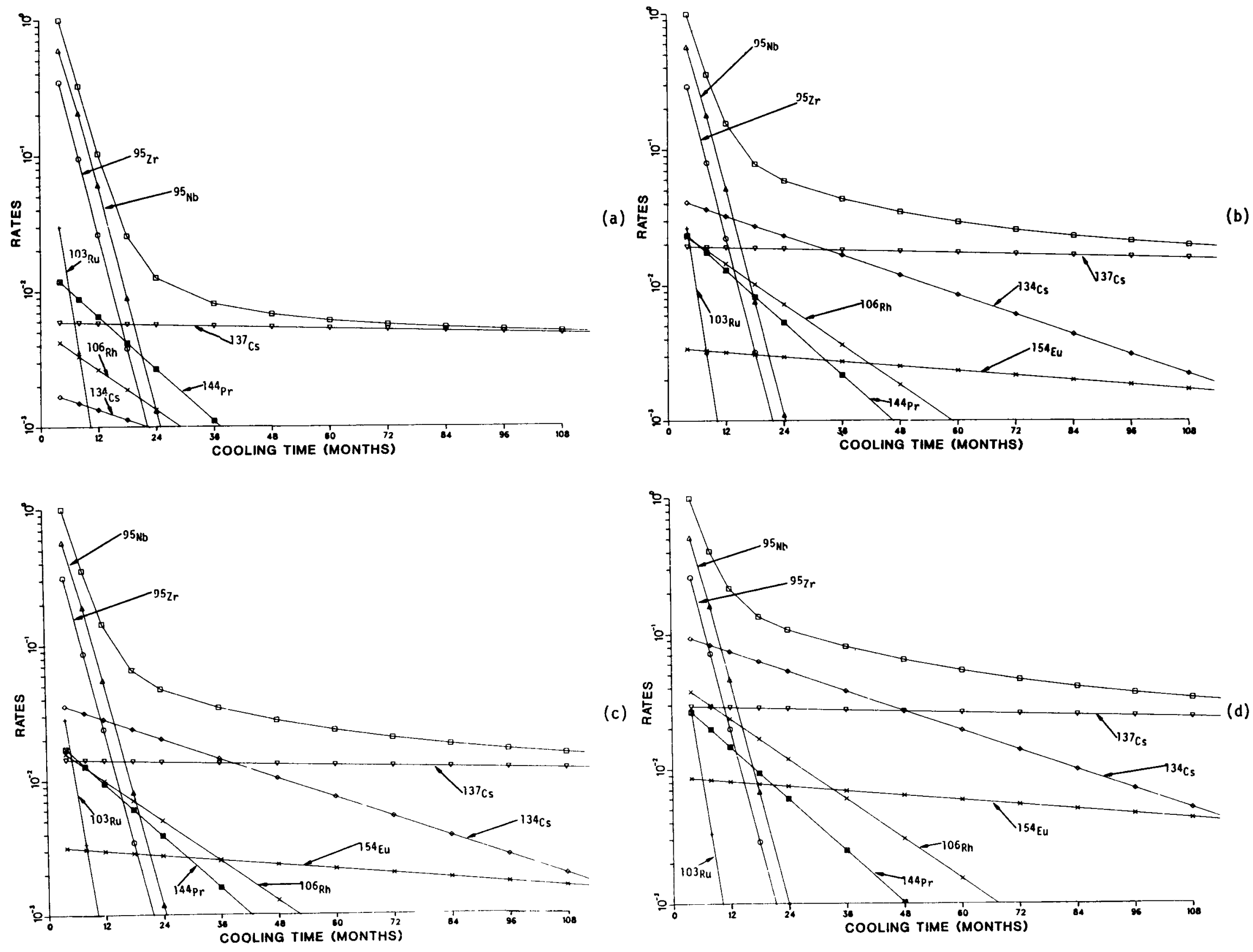

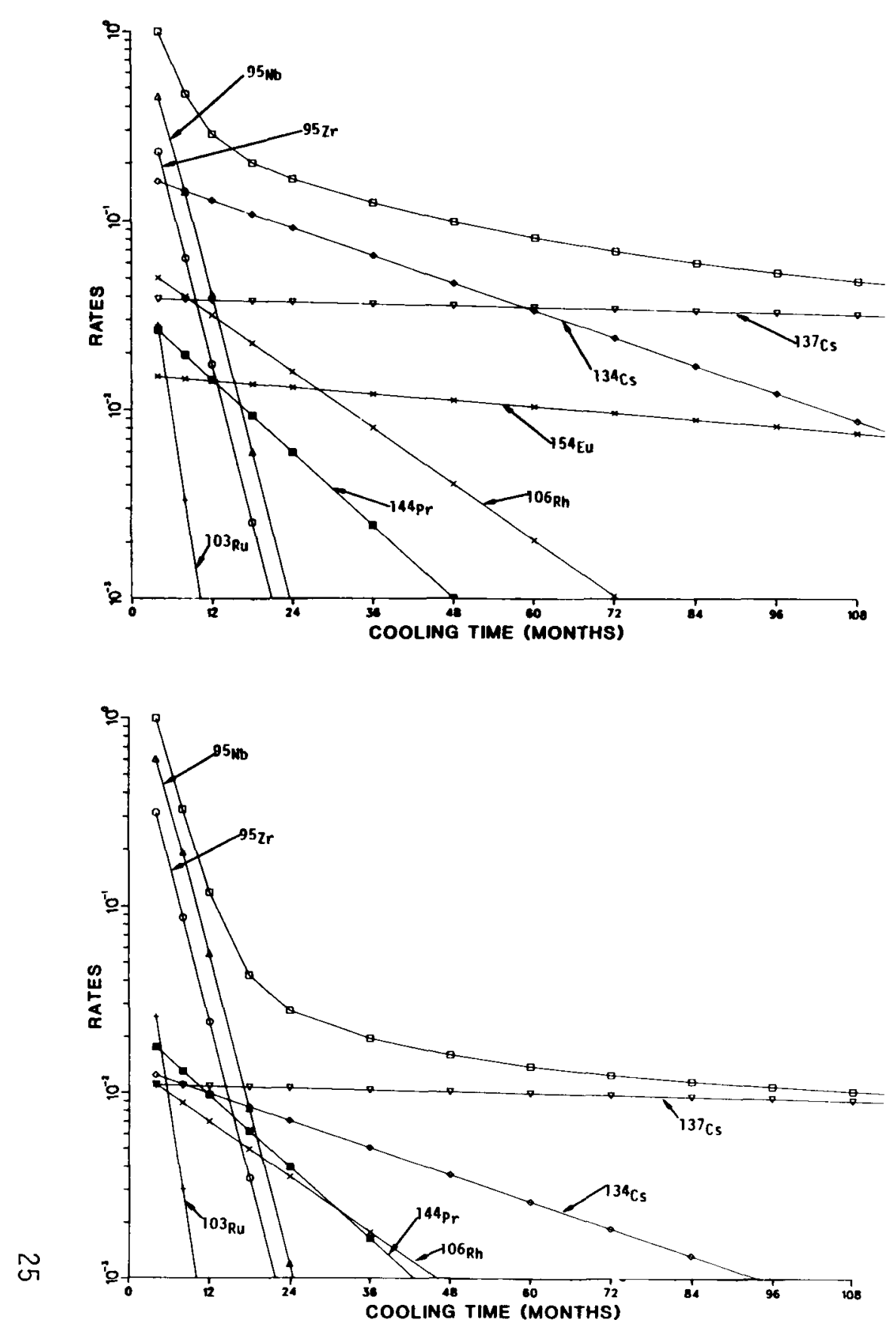

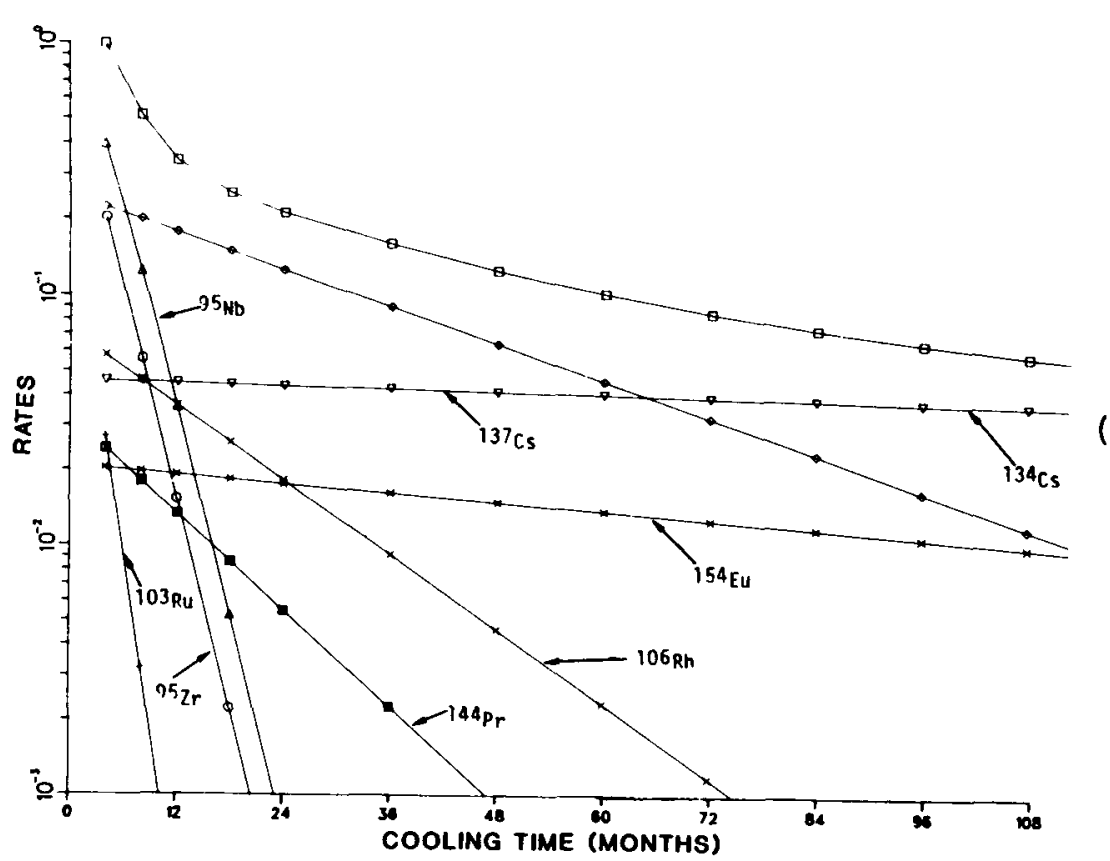

Fig. 6. Calculated relative dose rates in an airfilled chamber located $5 \mathrm{~cm}$ from the sides of irradiated fuel assemblies were divided by the appropriate exposures and plotted against cooling time to form the upper curves in these diagrams. The contributions from individual isotopes are shown by the straight lines; at any cooling time, the sum of the rates from all the isotopes equals the value at the upper curve. Each of these diagrams corresponds to the diagram in Fig. 5 with the same label; hence the range of exposures in each diagram is that given in the caption of Fig. 5 . 
3. Detector Distance. As the detector is moved away from the assembly, there is more intervening water to absorb and scatter the gamma rays. This certainly changes the detector's response. ${ }^{3,9}$ The cooling curve's shape (that is, the parameter b) is hardly affected by the detector distance, at least between distances of 2 and $20 \mathrm{~cm}$ where calculations were performed. In practice, larger or smaller distances are not likely to be used. When the curves were normalized at their 4 -month values, differences at later times were no more than $1 \%$.

A distance of only $2 \mathrm{~cm}$ of water is enough to limit the important contributors to a few gamma rays with combinations of high energy and high intensity; the same few gamma rays are the important contributors with $20 \mathrm{~cm}$ of water between the assembly and detector. The shape of the curve therefore remains virtually the same, regardless of the distance. A distance of $5 \mathrm{~cm}$ was chosen for the rest of the calculations.

4. Exposure. Both parameters of the cooling curve in Eq. (1) are sensitive to the range of exposures included in the fitting procedure. The effects of exposure on parameter a are not of interest because of $i$ ts relative nature. When calculated data from a wide range of exposures were fitted to the same curve, the fit was unsatisfactory. But when exposures were chosen from within a range of about $10 \mathrm{GWd} / \mathrm{tU}$, the fit to Eq. (1) was quite good. Figure 7 presents some examples of calculated data generated with different exposure ranges.

The value of $b$ was affected by the choice of the range of exposures; $b$ is strongly affected by changing from one set of low exposures to another, but takes on more uniform values after the exposures are above $20 \mathrm{GWd} / \mathrm{tU}$. A graph of $b$ as a function of exposure is given in Fig. 7 .

Al though it might be more convenient if $b$ remained nearly constant regardless of the exposures of the assemblies, the rather regular nature of the curve in Fig. 7 suggests that the value of $b$ could be used as an indicator of the exposure of the assemblies. However, for exposures above $40 \mathrm{GWd} / \mathrm{tU}$, the curve becomes too flat to indicate precisely any one exposure corresponding to a value of $b$. Below that rather high exposure, however, the value of $b$ seems sufficiently sensitive to the exposure.

With an irregular sampling of exposures among a set of assemblies, the value of $b$ probably would not indicate the exposures. But if a set of 


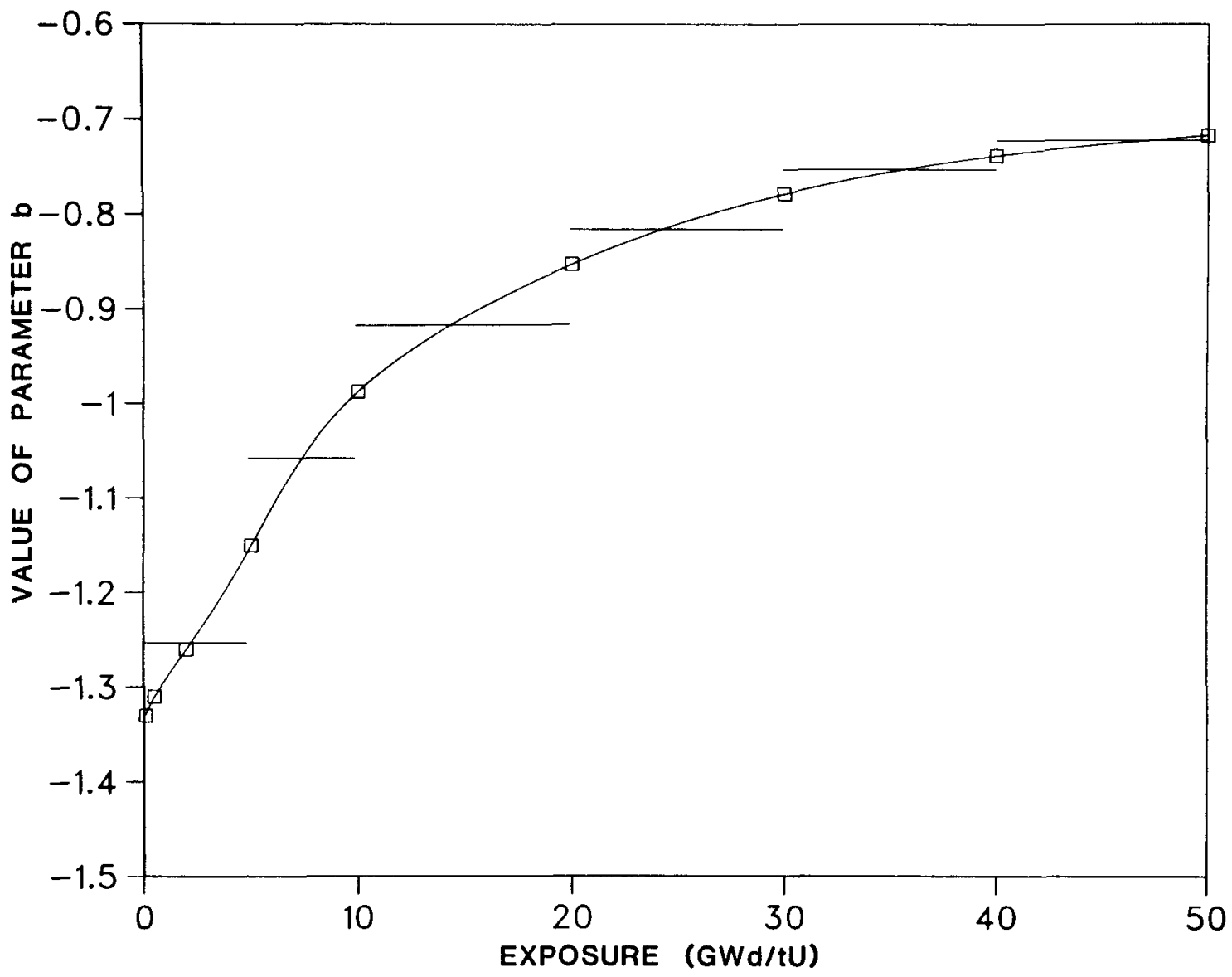

Fig. 7. When the power-1aw function of Eq. (1) in the text is fitted to calculated data (like the data shown in Fig. 6), the value of the parameter $b$ depends on the exposures of the assembilies used to produce the data. The data points indicated here by small squares show the values of $b$ found when $a 11$ assemblies have the same exposure. A smooth (spline) curve was passed through these points. The short horizontal lines that intersect this curve show the values of $b$ that were obtained for assemblies with various ranges of exposures; the ranges are given by the projection of the short lines onto the exposure axis. For exposures below $40 \mathrm{GWd} / \mathrm{tU}$, the horizontal lines are nearly bisected by the smooth curve, indicating that for a mixture of assemblies with a fairly uniform distribution of exposures over a range of about $10 \mathrm{GWd} / \mathrm{tU}$, the average exposure $c a n$ be deduced from the value of $b$.

assemblies is declared to have about the same exposure (within a range of about $10 \mathrm{GWd} / \mathrm{tU})$, then it might be possible to view $b$ as more than just a fitting parameter.

To test this idea, consider the measured data previously discussed in this report. With the Zion data, the fitted value of b was -0.83 . From Fig. 7 , 
this implies a range of exposures centered near $22 \mathrm{GWd} / \mathrm{tU}$; the actual range was from 19 to $36 \mathrm{GWd} / \mathrm{tU}$, which is centered in $27.5 \mathrm{GWd} / \mathrm{tU}$. This range of exposures of the measured assemblies is rather wide, but using only those assemblies with exposures from 19 to 34 or from 30 to $40 \mathrm{GWd} / \mathrm{tU}$ did not change b by more than 0.01 .

The results using the Morris data are even less encouraging. The fitted value of $b$ is -1.12 , which by Fig. 7 translates to exposures centered about $5 \mathrm{GWd} / \mathrm{tU}$. This is much too low; the actual exposures ranged from 18 to $40 \mathrm{GWd} / \mathrm{tU}$, and the curve suggests that $\mathrm{b}$ would be near -0.80 . Using only assemblies with exposures from 18 to $33 \mathrm{GWd} / \mathrm{tU}$ increased $b$ to only -1.05 . Note that no assemblies had short cooling times, so the fit is only over the portion of the curve that is rather flat when more of the curve is displayed (see Figs. 2 and 4); consequently, a value of $b$ could be produced that is quite different from that found with data points more widely spread in time. Furthermore, all the assemblies studied came from four different PWR reactors, so there could be variations in the calculated exposures that would not be present for assemblies from one facility.

Finally, the Vermont Yankee data for BWR assemblies produced a value of $b$ equal to -0.78 , implying exposures centered on $30 \mathrm{GWd} / \mathrm{tU}$. The actual exposures were from 8 to $29 \mathrm{GWd} / \mathrm{tU}$. If the fit is limited to those assemblies with exposures from 18 to $29 \mathrm{GWd} / \mathrm{tU}$, then $b$ is found to equal -0.79 . However, the values of $b$ were calculated for a PWR case, so its application to BWR assemblies might be suspect.

The average exposures deduced from $b$ through application of the curve in Fig. 7 are not satisfactorily accurate in these cases, although the Zion data are the least discouraging.

\section{CONCLUSIONS}

The analyses of both the experimental and calculational data show that the simple power-law cooling curve of Eq. (1) can be used as a check on the consistency of the operator-declared exposures and cooling times. The calculational data indicate that the exposure might be deduced from the parameter $b$ in the expression for the cooling curve, but this has not been demonstrated with the experimental data now available. In conjunction with neutron 
measurements that yield accurate exposure information, the cooling curve can provide a check on the values of the declared cooling times instead of simply verifying the internal consistency of the operator-declared values.

The shape of the curve, controlled by the parameter $b$, is not strongly sensitive to the initial enrichment of the fuel, the irradiation history, or the distance between the gross-gamma detector and the assembly (stored under waterl. The calculated data indicate that a wide range of exposures among the assemblies may affect the shape of the curve through $b$. The available measured data do not show such a sensitivity over the more restricted range of exposures encountered.

Use of a gross-gamma detector to check the accuracy of operator-declared values requires only simple equipment and short measurement times, especially when compared to using high-resolution gamma-ray spectroscopy. The detector may be limited to performing consistency checks after a single measurement session, but successive measurements at later cooling times can detect inaccuracies in the declared values that are not apparent after one measurement session. The finding of inconsistencies is enhanced by making a set of measurements as soon as possible after the assemblies are unloaded from the core.

With the addition of simple measurements of passive neutron emissions, absolute values of exposures and cooling times can be calculated and compared to the declared values.

More experience is needed with assemblies having a wide range of exposures and cooling times; the same assemblies should be examined on different occasions several months apart to determine that the same curve can be used for the assemblies throughout their cooling history.

\section{ACKNOWLEDGMENTS}

The many helpful suggestions from J. R. Phillips, G. E. Bosler, and J. K. Halbig of the Los Alamos National Laboratory on various aspects of this report are appreciated. The generosity of D. M. Lee, J. R. Phillips, and J. K. Halbig in allowing use of the previously unpublished data is gratefully acknowledged. 


\section{REFERENCES}

1. "The Structure and Content of Agreements Between the Agency and States Required in Connection with the Treaty on the Non-Proliferation of Nuclear Weapons," International Atomic Energy Agency document INFCIRC/153 (corrected) (June 1972), p. 9.

2. D. M. Lee, J. R. Phillips, S. T. Hsue, K. Kaieda, J. K. Halbig, E. G. Medina, and C. R. Hatcher, "A New Approach to the Examination of LWR Irradiated Fuel Assemblies Using Simple Gas Chamber Techniques," Los Alamos Scientific Laboratory report LA-7655-MS (ISPO-48) (March 1979).

3. D. D. Cobb, J. R. Phillips, G. E. Bosler, G. W. Eccleston, J. K. Halbig, C. R. Hatcher, and S. T. Hsue, "Nondestructive Verification and Assay Systems for Spent Fuels," Los Alamos National Laboratory report LA-9041, Vol. I (April 1982).

4. D. D. Cobb, J. R. Phillips, M. P. Baker, G. E. Bosler, G. W. Eccleston, J. K. Halbig, S. L. Klein, S. F. Klosterbuer, H. O. Menlove, C. A. Ostenak, and C. C. Thomas, Jr., "Nondestructive Verification and Assay Systems for Spent Fuels," Los Alamos National Laboratory report LA-9041, Vol. II (Apri1 1982).

5. J. R. Phillips, J. K. Halbig, D. M. Lee, S. E. Beach, T. R. Bement, E. Dermendjiev, C. R. Hatcher, K. Kaieda, and E. G. Medina, "Application of Nondestructive Gamma-Ray and Neutron Techniques for the Safeguarding of Irradiated Fuel Materials," Los Alamos Scientific Laboratory report LA-8212 (ISPO-77) (May 1980).

6. J. R. Phillips, G. E. Bosler, J. K. Halbig, S. F. Klosterbuer, D. M. Lee, and H. 0. Menlove, "Neutron Measurement Techniques for the Nondestructive Analysis of Irradiated Fuel Assemblies," Los Alamos National Laboratory report LA-9002-MS (ISP0-156) (November 1981).

7. G. E. Bosler, J. R. Phillips, W. B. Wilson, R. J. LaBauve, and T. R. England, "Production of Actinide Isotopes in Simulated PWR Fuel and Their Influence on Inherent Neutron Emission," Los Alamos National Laboratory report LA-9343 (July 1982).

8. J. R. Phillips and G. E. Bosler, "Calculated Gamma-Ray Responses to Sources Placed in PWR Fuel Assemblies," in "Safeguards and Security Status Report, August 1981-January 1982," J. P. Shipley, Comp., Los Alamos National Laboratory report LA-9373-PR (September 1982), p. 44 .

9. P. M. Rinard, "Gamma Doses from Irradiated Assemblies Under Water," Los Alamos Scientific Laboratory report LA-7914-MS (July 1979).

10. E. Dermendjiev, A. Filatkin, K. Kaieda, V. Utyatnikov, and G. Kaschiev, "Passive Neutron and Gross Gamma-Ray Safeguards Verification Measurement of WWER-440 Spent Fuel," International Symposium on Recent Advances in Nuclear Materials Safeguards, International Atomic Energy Agency report IAEA-SM-260/42 (November 1982). 
11. S. T. Hsue, T.W. Crane, W. L. Talbert, Jr., and J. C. Lee, "Nondestructive Assay Methods for Irradiated Nuclear Fuels, "Los Alamos Scientific Laboratory report LA-6923 (January 1978).

12. J. R. Phillips, T. R. Bement, C. R. Hatcher, S. T. Hsue, and D. M. Lee, "Nondestructive Verification of the Exposure of Heavy-Water Reactor Fuel Elements," Los Alamos National Laboratory report LA-9432-MS (June 1982).

13. T. R. England, W. B. Wilson, and M. G. Stamatelatos, "Fission Product Data for Thermal Reactors, Part 1: A Data Set for EPRI-CINDER Using ENDF/ B-IV," Electric Power Research Institute report EPRI NP-356, Part 1 (December 1976). Also published as Los Alamos Scientific Laboratory report LA-6745-MS (December 1976).

14. T. R. England, W. B. Wilson, and M. G. Stamatelatos, "Fission Product Data for Thermal Reactors, Part 2: Users' Manual for EPRI-CINDER Code and Data," Electric Power Research Institute report EPRI NP-356, Part 2 (December 1976). Also published as Los Alamos Scientific Laboratory report LA-6746-MS (December 1976).

15. W. B. Wilson, R. J. LaBauve, and T. R. England, Los Alamos National Laboratory memo T-2-1166 to A. E. Norris, March 17, 1981.

16. W. E. Deming, Statistical Adjustment of Data (John Wiley and Sons, Inc., New York, $1 9 4 3 \longdiv { \text { . } }$

17. J. R. Wolberg, Prediction Analysis (D. Van Nostrand, Princeton, New Jersey, 1967).

18. J. F. Kenney and E. S. Keeping, Mathematics of Statistics Vol. I (D. Van Nostrand, Princeton, New Jersey, T954/.

19. N. R. Draper and H. Smith, Applied Regression Analysis (John Wiley and Sons, Inc., New York, 1966).

20. M. G. Natrella, "Experimental Statistics," National Bureau of Standards Handbook 91 United States Department of Commerce, Washington, DC, (1963).

21. C. C. Thomas, Jr., D. D. Cobb, and C. A. Ostenak, "Spent-Fuel Composition: A Comparison of Predicted and Measured Data," Los Alamos National Laboratory report LA-8764-MS (March 1981).

22. J. R. Phillips, G. E. Bosler, J. K. Halbig, S. F. Klosterbuer, and H. 0. Menlove, "Nondestructive Verification with Minimal Movement of Irradiated Light-Water Reactor Fuel Assemblies," Los Alamos National Laboratory report LA-9438-MS (ISP0-172) (October 1982).

23. G. R. Keepin, Ed., "Nuclear Safeguards Research and Development Program Status Report, July-September 1980," Los Alamos National Laboratory report LA-8590-PR (March 1981 ). 
24. C. N. Henry, Comp., "Nuclear Safeguards Research and Development Program Status Report, October 1980-January 1981," Los A1 amos National Laboratory report LA-8870-PR (November 1981).

25. C. N. Henry and R. B. Walton, Comp., "Program Status Report, Safeguards and Security Research and Development, February-July 1981," Los A1amos National Laboratory report LA-9110-PR (Apri1 1982), p. 38.

26. J. R. Phillips, J. K. Halbig, S. F. Klosterbuer, and P. M. Rinard, Los Alamos National Laboratory memo Q-1-82-516/0082C to J. Shipley, Q-DO/SG, Los Alamos, July 8, 1982.

27. P. M. Rinard, G. E. Bosler, and J. R. Phillips, "Calculated Neutron Source Spectra from Selected Irradiated PWR Fuel Assemblies," Los Alamos National Laboratory report LA-9125-MS (December 1981). 